\title{
Serum Levels of Asymmetric Dimethylarginine, Vascular Endothelial Growth Factor, and Nitric Oxide Metabolite Levels in Preeclampsia Patients
}

\author{
Marjan Noorbakhsh, ${ }^{1,2}$ Maryam Kianpour, ${ }^{3,4}$ and Mehdi Nematbakhsh ${ }^{1,5,6}$ \\ ${ }^{1}$ Water \& Electrolytes Research Center, Isfahan University of Medical Sciences, Isfahan 81745, Iran \\ ${ }^{2}$ Department of Obstetrics and Gynecology, Isfahan University of Medical Sciences, Isfahan 81745, Iran \\ ${ }^{3}$ Nursing \& Midwifery Care Research Center, Isfahan University of Medical Sciences, Isfahan 81745, Iran \\ ${ }^{4}$ Department of Midwifery, Isfahan University of Medical Sciences, Isfahan 81745, Iran \\ ${ }^{5}$ Department of Physiology, Isfahan University of Medical Sciences, Isfahan 81745, Iran \\ ${ }^{6}$ Isfahan-MN Institute of Basic \& Applied Sciences Research, Isfahan 81546, Iran
}

Correspondence should be addressed to Mehdi Nematbakhsh; nematbakhsh@med.mui.ac.ir

Received 6 June 2013; Accepted 24 July 2013

Academic Editors: M. Kühnert and S. Palomba

Copyright (C) 2013 Marjan Noorbakhsh et al. This is an open access article distributed under the Creative Commons Attribution License, which permits unrestricted use, distribution, and reproduction in any medium, provided the original work is properly cited.

\begin{abstract}
Background. Hypertensive disorder generally complicates 5-10 percent of all pregnancies. Angiogenic growth factors may be helpful for the diagnosis and prediction of preeclampsia. Therefore, in this study we attempted to determine the serum levels of asymmetric dimethylarginine (ADMA), vascular endothelial growth factor (VEGF), and nitric oxide (NO) metabolite (nitrite) in preeclampsia patients and compared the levels with those obtained from normal pregnant women. Methods. Ninety pregnant women (19-33 years old) in two groups of preeclampsia and normal were considered during 2012. The levels of ADMA, VEGF, and nitrite were measured in maternal serum samples using ELISA kits. Results. Significant increase of VEGF and nitrite levels was observed in preeclampsia patients when compared with other groups $(P<0.05)$. The serum level of ADMA demonstrated a similar increased trend in preeclampsia patients; however, the increase was not statistically significant $(P=0.08)$. Conclusion. The findings reveal that the elevation of serum levels of VEGF and nitrite and possibly ADMA may be involved in the pathogenesis of preeclampsia.
\end{abstract}

\section{Introduction}

Hypertensive disorder is generally the most common disease and cause of death in pregnancy and complicates 5-10\% of all pregnancies. Furthermore, the pregnancy syndrome preeclampsia complicates approximately $3-7 \%$ of all pregnancies, and the syndrome becomes a major contributor of death [1-4]. Preeclampsia generally is recognized by deficient uteroplacental perfusion $[5,6]$, and some risk factors such as obesity, multifetal gestations, maternal age above 35, and African-American ethnicity are associated with this syndrome [7-9]. The association between pregnancy and hypertension and its effects on mother and child life remain a subject of intensive researches for many years, and no definite solution was achieved yet. Preeclampsia often affects young and nulliparous women, and its incidence is influenced by race and genetic predispositions [10]. The role of the renin-angiotensin system and angiogenic and antiangiogenic biomarkers of placental origin has been described in pathogenesis of preeclampsia [11]. However, there is no definite biomarker to be considered as a sensitive parameter to control the disease severity. Nitric oxide (NO) is a potent vasodilator that is synthesized from L-arginine by the NO synthase and endothelial cells [12] and regulates the vascular tone and blood flow in the vascular smooth muscles. The endothelium-released NO is influenced by hypertension, and it is considered as a factor of endothelial functions $[13,14]$. NO could promote the release of an important angiogenesis mediator; vascular endothelial growth factor (VEGF). VEGF is a potent endothelial cell-specific mitogen that promotes vascular hyperpermeability, and vasodilation [15-18]. Asymmetric dimethylarginine (ADMA) is an antiangiogenesis 
factor $[19,20]$ that decreases the expression of VEGF in endothelial cells [21] and may interrupt the NO-producing activity of NO synthase.

Chedraui et al. measured the serum levels of NO, ADMA, and VEGF in severe preeclampsia and found positive correlation between $\mathrm{NO}$ and ADMA among preeclampsia cases, and the NO levels were significantly different in the artery and vein of umbilical vessels. Moreover, the level of VEGF was significantly lower in the artery but not in the vein in preeclampsia cases [22]. Other studies indicated an increase in ADMA level and a decrease in NO levels [23] or decrease in the level of both factors [24] in preeclampsia. Furthermore, the importance of NO has been emphasized in preeclampsia $[25,26]$. ADMA may have a clinical significance $[27,28]$, and it is a potential biomarker to identify pregnant women at the risk of developing preeclampsia [29]. Angiogenic growth factors such as VEGF may be helpful for the diagnosis and prediction of preeclampsia [30], and it may be responsible for impaired vascular development [31]. Still, there is no well-documented data that explains how NO, ADMA, and VEGF levels vary in preeclampsia patients. So, we attempted to determine the serum levels of these biomarkers in serum samples of preeclampsia patients and compared them with those obtained from normal pregnant women.

\section{Materials and Methods}

2.1. Patients. This study included patients with and without preeclampsia referred to obstetrics and gynecology clinics of Isfahan University of Medical Sciences during 2012. This study was approved by the Ethical Committee of Isfahan University of Medical Sciences.

All pregnant subjects were nulliparous healthy women without any known preexisting medical complications. Exclusion criteria included multiple gestation, prior preeclampdsia, and preexisting medical conditions such as diabetes, chronic hypertension, and renal disease. Forty-five women with preeclampsia (aged $24.7 \pm 0.6$ years) and 45 women without preeclampsia (aged $24.5 \pm 0.5$ years) were selected. Preeclampsia was diagnosed by the presence of gestational hypertension, proteinuria, and hyperuricemia beginning after the 20th week of pregnancy with resolution of gestational hypertension and postpartum proteinuria. Gestational hypertension was defined as a new onset increase in blood pressure including an absolute systolic blood pressure (BP) $\geq 140 \mathrm{mmHg}$ and/or diastolic BP $\geq 90 \mathrm{mmHg}$ after 20 weeks of gestation. Proteinuria was defined as $\geq 300 \mathrm{mg}$ per 24 -hour urine collection, $\geq 2+$ protein on voided urine sample, $\geq 1+$ protein on catheterized urine specimen, or a proteincreatinine ratio of $\geq 0.3$. The official informed consent was obtained from all subjects, and the demographic data were collected.

2.2. Measurements. Maternal blood sample was obtained and centrifuged. The serum samples were collected and stored at $-20^{\circ} \mathrm{C}$ for later analysis. The serum levels of VEGF were measured using an enzyme immunoassay kit (Immuno-Biological Laboratory Co., Japan). Briefly, the kit is a solid-phase sandwich ELISA using specific polyclonal and monoclonal antibodies, and the coloring agent was tetramethylbenzidine (TMB). The absorbance at $450 \mathrm{~nm}$ is in proportion to the VEGF concentration using the standard curve.

The serum levels of nitrite (stable NO metabolite) were measured using a colorimetric assay kit (Promega Corporation, USA) that involves the Griess reaction. Briefly, after adding sulphanilamide solution and incubation, $N$-1-naphtylethylenediamine dihydrochloride solution was added. Then, the absorbance was measured by a microreader at $540 \mathrm{~nm}$ wavelength. The nitrite concentrations of the samples were determined by comparison to the nitrite standard reference curve.

The serum levels of ADMA were measured using an enzyme immunoassay kit (DLD Diagnostika GmbH, Germany). Briefly, ADMA in the samples competes with solid phase-bound ADMA for a fixed number of rabbit antiADMA. The anti-rabbit/peroxidase was used to detect the antibody bound to the solid-phase ADMA, which is inversely proportional to the ADMA concentration of serum or peritoneal fluid.

2.3. Statistical Analyses. The data are reported as mean \pm SEM. The parameters between case and control groups were compared using unpaired $t$-tests, and $P$ value less than 0.05 was considered statistically significant.

\section{Results}

The data of serum levels of VEGF, nitrite, and ADMA for the patients with preeclampsia (case) and pregnant women without preeclampsia (control) is demonstrated in Figure 1. A significant increase in VEGF and nitrite levels was observed in preeclampsia patients when compared with the control group $(P<0.05)$. The serum level of ADMA demonstrated a similar increased trend in preeclampsia patients, but the difference was not statistically significant $(P=0.08)$.

\section{Discussion}

Our observation indicated that serum levels of VEGF and nitrite were higher in patients with preeclampsia (case) than normotensive pregnant women (control). In addition, the serum level of ADMA was nonsignificantly different between the case and control groups. The increase of VEGF in preeclampsia patients was reported before [32, 33] due to endothelial activation. However, the level of free VEGF decreased in preeclampsia subjects possibly because of endothelial dysfunction [34]. In the current study, we measured the total VEGF; bounding and free levels in serum, which was detectable by ELISA assay. Therefore, higher levels of VEGF in preeclampsia subject were expected which is consistent with the findings reported in previous studies [32, 33]. Moreover, $\mathrm{NO}$ level increases in hypertension condition, and about $50 \%$ of our patients had a blood pressure above $160 / 90 \mathrm{mmHg}$, which may increase the serum level of NO. However, there are some controversies for alteration of $\mathrm{NO}$ 

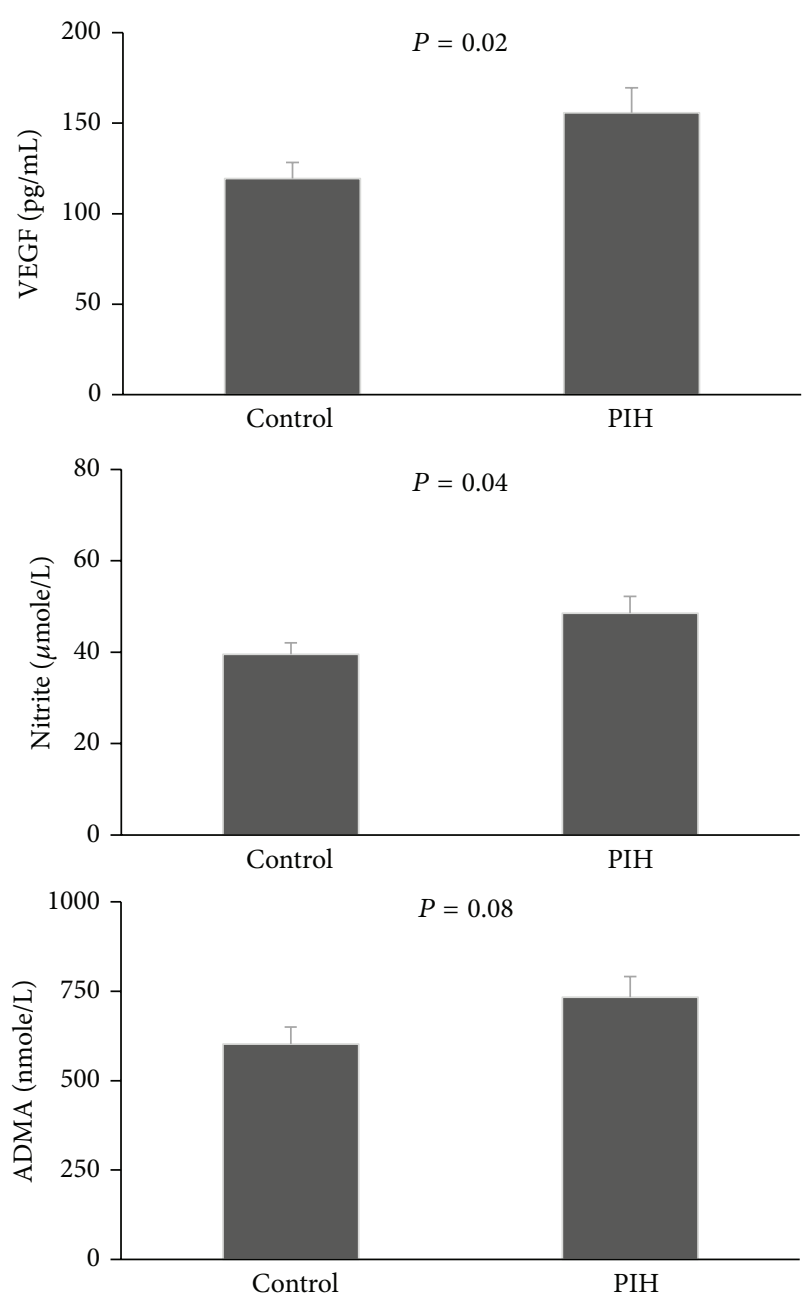

FIGURE 1: Serum levels of VEGF, nitrite, and ADMA in patients with $\mathrm{PIH}$ with normal matched pregnant women. The data is shown as mean \pm SEM and was compared using two-tailed Student's $t$-test analysis.

in preeclampsia patients. Some reports indicated decreased NO level [35-39], and no change in NO level was detected by others [40-44]. The reason for such observation may be related to increase of nitrite excretion in the urine or decrease of placental NO synthase activation [45] in pregnant women with preeclampsia. In addition, it is also reported that the serum level of NO is related to gestational age, which become at maximum level in gestational age of 35 to 36 weeks [46]. We measured the serum level of nitrite as one of the stable NO metabolite, which was increased in the case group. Two reasons may contribute to such finding. First, the gestational age of our patients was $34.8 \pm 2.4$ weeks, and possibly at this age the serum level of NO was high [46], and second, we measured one of the NO metabolites, nitrite. Different results would possibly be obtained if other metabolite; nitrate was also measured. One limitation for our study was lack of gestational age matching between the two groups because the preeclampsia patients were included in the study as soon as the sign of disease appeared.
ADMA is an antiangiogenesis factor that decreases VEGF expression in endothelial cells and prevents the formation of NO from NOS. Increase of ADMA in endotheliumdependent vascular dysfunction was detected in diabetic, hypertensive, and hypercholesterolemic patients [20, 47, 48]. It is reported that ADMA may decrease at the beginning of normal pregnancy [49], but under the preeclampsia condition its concentration increases [50-52], which may be associated with the disease intensity [50]. It seems that ADMA is involved in preeclampsia pathogenesis because inhibition of NO synthesis in rodents during pregnancy produces signs similar to those of preeclampsia [53-55]. In the current study, the serum level of ADMA nonsignificantly increased in the case group. The reason for such nonsignificant elevation may related to the increase of $\mathrm{NO}$ level in these patients.

\section{Conclusion}

The findings reveal that elevation of serum levels of VEGF and nitrite and possibly ADMA may be involved in the pathogenesis of preeclampsia, and these markers may be helpful for the diagnosis of the disease.

\section{Conflict of Interests}

The authors do not have any direct financial relationship with the commercial identities mentioned in this paper. So, the authors have no conflict of interests.

\section{Acknowledgment}

This research was supported by the Isfahan University of Medical Sciences (Grant no. 290203).

\section{References}

[1] L. K. Wagner, "Diagnosis and management of preeclampsia," American Family Physician, vol. 70, no. 12, pp. 2317-2324, 2004.

[2] B. M. Sibai, "Diagnosis and management of gestational hypertension and preeclampsia," Obstetrics and Gynecology, vol. 102, no. 1, pp. 181-192, 2003.

[3] ACOG practice bulletin, "Diagnosis and management of preeclampsia and eclampsia. Number 33, January 2002. American College of Obstetricians and Gynecologists," International Journal of Gynecology \& Obstetric, vol. 77, no. 1, pp. 67-75, 2002.

[4] M. D. Lindheimer and A. I. Katz, "Preeclampsia: pathophysiology, diagnosis, and management," Annual Review of Medicine, vol. 40, pp. 233-250, 1989.

[5] J. C. Kingdom and P. Kaufmann, "Oxygen and placental vascular development," Advances in Experimental Medicine and Bio$\log y$, vol. 474, pp. 259-275, 1999.

[6] J. M. Roberts, "Objective evidence of endothelial dysfunction in preeclampsia," American Journal of Kidney Diseases, vol. 33, no. 5, pp. 992-997, 1999.

[7] A. Conde-Agudelo and J. M. Belizán, "Risk factors for preeclampsia in a large cohort of Latin American and Caribbean women," British Journal of Obstetrics and Gynaecology, vol. 107, no. 1 , pp. $75-83,2000$. 
[8] B. M. Sibai, M. Ewell, R. J. Levine et al., "Risk factors associated with preeclampsia in healthy nulliparous women. The Calcium for Preeclampsia Prevention (CPEP) Study Group," American Journal of Obstetrics \& Gynecology, vol. 177, no. 5, pp. 1003-1010, 1997.

[9] J. J. Walker, “Pre-eclampsia," The Lancet, vol. 356, no. 9237, pp. 1260-1265, 2000.

[10] I. L. Sargent, A. M. Borzychowski, and C. W. G. Redman, "Immunoregulation in normal pregnancy and pre-eclampsia: an overview," Reproductive BioMedicine Online, vol. 13, no. 5, pp. 680-686, 2006.

[11] D. M. Shah, "Preeclampsia: new insights," Current Opinion in Nephrology and Hypertension, vol. 16, no. 3, pp. 213-220, 2007.

[12] S. M. Sladek, R. R. Magness, and K. P. Conrad, "Nitric oxide and pregnancy," American Journal of Physiolog, vol. 272, no. 2, part 2, pp. R441-R463, 1997.

[13] L. Myatt, A. S. Brewer, G. Langdon, and D. E. Brockman, "Attenuation of the vasoconstrictor effects of thromboxane and endothelin by nitric oxide in the human fetal-placental circulation," American Journal of Obstetrics \& Gynecology, vol. 166, no. 1, part 1, pp. 224-230, 1992.

[14] C. P. Weiner, L. P. Thompson, K. Z. Liu, and J. E. Herrig, "Endothelium-derived relaxing factor and indomethacin-sensitive contracting factor alter arterial contractile responses to thromboxane during pregnancy," American Journal of Obstetrics \& Gynecology, vol. 166, no. 4, pp. 1171-1181, 1992.

[15] D. S. Charnock-Jones, A. M. Sharkey, J. Rajput-Williams et al., "Identification and localization of alternately spliced mRNAs for vascular endothelial growth factor in human uterus and estrogen regulation in endometrial carcinoma cell lines," Biology of Reproduction, vol. 48, no. 5, pp. 1120-1128, 1993.

[16] K. A. Houck, N. Ferrara, J. Winer, G. Cachianes, B. Li, and D. W. Leung, "The vascular endothelial growth factor family: identification of a fourth molecular species and characterization of alternative splicing of RNA," Molecular Endocrinology, vol. 5, no. 12, pp. 1806-1814, 1991.

[17] M. S. Pepper, N. Ferrara, L. Orci, and R. Montesano, "Vascular endothelial growth factor (VEGF) induces plasminogen activators and plasminogen activator inhibitor-1 in microvascular endothelial cells," Biochemical and Biophysical Research Communications, vol. 181, no. 2, pp. 902-906, 1991.

[18] E. N. Unemori, N. Ferrara, E. A. Bauer, and E. P. Amento, "Vascular endothelial growth factor induced interstitial collagenase expression in human endothelial cells," Journal of Cellular Physiology, vol. 153, no. 3, pp. 557-562, 1992.

[19] J. P. Cooke, "Does ADMA cause endothelial dysfunction?" Arteriosclerosis, Thrombosis, and Vascular Biology, vol. 20, no. 9, pp. 2032-2037, 2000.

[20] J. P. Cooke, "Asymmetrical dimethylarginine: the Über marker?" Circulation, vol. 109, no. 15, pp. 1813-1818, 2004.

[21] C. L. Smith, G. M. Birdsey, S. Anthony, F. I. Arrigoni, J. M. Leiper, and P. Vallance, "Dimethylarginine dimethylaminohydrolase activity modulates ADMA levels, VEGF expression, and cell phenotype," Biochemical and Biophysical Research Communications, vol. 308, no. 4, pp. 984-989, 2003.

[22] P. Chedraui, E. J. Solis, G. Bocci et al., "Feto-placental nitric oxide, asymmetric dimethylarginine and vascular endothelial growth factor (VEGF) levels and VEGF gene polymorphisms in severe preeclampsia," Journal of Maternal-Fetal and Neonatal Medicine, vol. 26, no. 3, pp. 226-232, 2013.
[23] B. Demir, S. Demir, S. Pasa et al., "The role of homocysteine, asymmetric dimethylarginine and nitric oxide in preeclampsia," Journal of Obstetrics \& Gynaecology, vol. 32, no. 6, pp. 525-528, 2012.

[24] E. Dikensoy, O. Balat, S. Pence, A. Balat, M. Cekmen, and M. Yurekli, "The changes of plasma malondialdehyde, nitric oxide, and adrenomedullin levels in patients with preeclampsia," Hypertension in Pregnancy, vol. 28, no. 4, pp. 383-389, 2009.

[25] K. Matsubara, Y. Matsubara, S. Hyodo, T. Katayama, and M. Ito, "Role of nitric oxide and reactive oxygen species in the pathogenesis of preeclampsia," Journal of Obstetrics and Gynaecology Research, vol. 36, no. 2, pp. 239-247, 2010.

[26] E. Poniedzialek-Czajkowska, B. Marciniak, Z. Kimber-Trojnar, B. Leszczyńska-Gorzelak, and J. Oleszczuk, "Nitric oxide in normal and preeclamptic pregnancy," Current Pharmaceutical Biotechnology, vol. 12, no. 5, pp. 743-749, 2011.

[27] A. Pettersson, T. Hedner, and I. Milsom, "Increased circulating concentrations of asymmetric dimethyl arginine (ADMA), an endogenous inhibitor of nitric oxide synthesis, in preeclampsia," Acta Obstetricia et Gynecologica Scandinavica, vol. 77, no. 8, pp. 808-813, 1998.

[28] M. P. Siroen, T. Teerlink, R. J. Nijveldt, H. A. Prins, M. C. Richir, and P. A. van Leeuwen, "The clinical significance of asymmetric dimethylarginine," Annual Review of Nutrition, vol. 26, pp. 203228, 2006.

[29] R. H. Böger, A. Diemert, E. Schwedhelm, N. Lüneburg, R. Maas, and K. Hecher, "The role of nitric oxide synthase inhibition by asymmetric dimethylarginine in the pathophysiology of preeclampsia," Gynecologic and Obstetric Investigation, vol. 69, no. 1, pp. 1-13, 2010.

[30] S. Verlohren, H. Stepan, and R. Dechend, "Angiogenic growth factors in the diagnosis and prediction of pre-eclampsia," Clinical Science, vol. 122, no. 2, pp. 43-52, 2012.

[31] A. L. Tranquilli, V. Bezzeccheri, S. R. Giannubilo, C. Scagnoli, L. Mazzanti, and G. G. Garzetti, "Amniotic vascular endothelial growth factor (VEGF) and nitric oxide (NO) in women with subsequent preeclampsia," European Journal of Obstetrics Gynecology and Reproductive Biology, vol. 113, no. 1, pp. 17-20, 2004.

[32] P. N. Baker, J. Krasnow, J. M. Roberts, and K. T. Yeo, "Elevated serum levels of vascular endothelial growth factor in patients with preeclampsia," Obstetrics and Gynecology, vol. 86, no. 5, pp. 815-821, 1995.

[33] A. M. Sharkey, J. C. Cooper, J. R. Balmforth et al., "Maternal plasma levels of vascular endothelial growth factor in normotensive pregnancies and in pregnancies complicated by preeclampsia," European Journal of Clinical Investigation, vol. 26, no. 12, pp. 1182-1185, 1996.

[34] B. Varughese, N. Bhatla, R. Kumar, S. N. Dwivedi, and R. Dhingra, "Circulating angiogenic factors in pregnancies complicated by pre-eclampsia," National Medical Journal of India, vol. 23, no. 2, pp. 77-81, 2010.

[35] S. P. Brennecke, N. M. Gude, J. L. Di Iulio, and R. G. King, "Reduction of placental nitric oxide synthase activity in preeclampsia," Clinical Science, vol. 93, no. 1, pp. 51-55, 1997.

[36] J. W. Choi, M. W. Im, and S. H. Pai, "Nitric oxide production increases during normal pregnancy and decreases in preeclampsia," Annals of Clinical and Laboratory Science, vol. 32, no. 3, pp. 257-263, 2002.

[37] M. Faxén, H. Nisell, and K.-R. Kublickiene, "Altered mRNA expression of ecNOS and iNOS in myometrium and placenta from women with preeclampsia," Archives of Gynecology and Obstetrics, vol. 265, no. 1, pp. 45-50, 2001. 
[38] J. Rowe, S. Campbell, and E. D. Gallery, "Plasma from preeclamptic women stimulates decidual endothelial cell growth and prostacyclin but not nitric oxide production: close correlation of prostacyclin and thromboxane production," Journal of the Society for Gynecologic Investigation, vol. 8, no. 1, pp. 32-38, 2001.

[39] J. R. Steinert, A. W. Wyatt, L. Poston, R. Jacob, and G. E. Mann, "Preeclampsia is associated with altered $\mathrm{Ca}^{2+}$ regulation and NO production in human fetal venous endothelial cells," The FASEB Journal, vol. 16, no. 7, pp. 721-723, 2002.

[40] P. T. Ayuk, D. Theophanous, S. W. D’Souza, C. P. Sibley, and J. D. Glazier, "L-arginine transport by the microvillous plasma membrane of the syncytiotrophoblast from human placenta in relation to nitric oxide production: effects of gestation, preeclampsia, and intrauterine growth restriction," Journal of Clinical Endocrinology and Metabolism, vol. 87, no. 2, pp. 747751, 2002.

[41] R. Di Iorio, E. Marinoni, S. Emiliani, B. Villaccio, and E. V. Cosmi, "Nitric oxide in preeclampsia: lack of evidence for decreased production," European Journal of Obstetrics Gynecology and Reproductive Biology, vol. 76, no. 1, pp. 65-70, 1998.

[42] F. M. Diejomaoh, A. E. Omu, N. Al-Busiri et al., "Nitric oxide production is not altered in preeclampsia," Archives of Gynecology and Obstetrics, vol. 269, no. 4, pp. 237-243, 2004.

[43] F. Scalera, D. Schlembach, and E. Beinder, "Production of vasoactive substances by human umbilical vein endothelial cells after incubation with serum from preeclamptic patients," European Journal of Obstetrics Gynecology and Reproductive Biology, vol. 99, no. 2, pp. 172-178, 2001.

[44] F. F. Yanik, R. Amanvermez, I. Koçak, A. Yanik, and C. Çelik, "Serum nitric oxide and glutathione levels in preeclamptic and normotensive women during labor," Gynecologic and Obstetric Investigation, vol. 51, no. 2, pp. 110-115, 2001.

[45] J. V. Garmendia, Y. Gutiérrez, I. Blanca, N. E. Bianco, and J. B. de Sanctis, "Nitric oxide in different types of hypertension during pregnancy," Clinical Science, vol. 93, no. 5, pp. 413-421, 1997.

[46] T. Jo, Y. Takauchi, Y. Nakajima, K. Fukami, H. Kosaka, and N. Terada, "Maternal or umblical venous levels of nitrite/nitrate during pregnancy and at delivery," In Vivo, vol. 12, no. 5, pp. 523-526, 1998.

[47] V. Achan, M. Broadhead, M. Malaki et al., "Asymmetric dimethylarginine causes hypertension and cardiac dysfunction in humans and is actively metabolized by dimethylarginine dimethylaminohydrolase," Arteriosclerosis, Thrombosis, and Vascular Biology, vol. 23, no. 8, pp. 1455-1459, 2003.

[48] R. H. Böger, S. M. Bode-Böger, A. Szuba et al., "Asymmetric dimethylarginine (ADMA): a novel risk factor for endothelial dysfunction: its role in hypercholesterolemia," Circulation, vol. 98, no. 18, pp. 1842-1847, 1998.

[49] D. P. Holden, S. A. Fickling, G. S. Whitley, and S. S. Nussey, "Plasma concentrations of asymmetric dimethylarginine, a natural inhibitor of nitric oxide synthase, in normal pregnancy and preeclampsia," American Journal of Obstetrics \& Gynecology, vol. 178, no. 3, pp. 551-556, 1998.

[50] J. Ellis, U. B. Wennerholm, A. Bengtsson et al., "Levels of dimethylarginines and cytokines in mild and severe preeclampsia," Acta Obstetricia et Gynecologica Scandinavica, vol. 80, no. 7, pp. 602-608, 2001.

[51] K. Braekke, P. M. Ueland, N. K. Harsem, and A. C. Staff, "Asymmetric dimethylarginine in the maternal and fetal circulation in preeclampsia," Pediatric Research, vol. 66, no. 4, pp. 411-415, 2009.
[52] M. D. Savvidou, A. D. Hingorani, D. Tsikas, J. C. Frölich, P. Vallance, and K. H. Nicolaides, "Endothelial dysfunction and raised plasma concentrations of asymmetric dimethylarginine in pregnant women who subsequently develop pre-eclampsia," The Lancet, vol. 361, no. 9368, pp. 1511-1517, 2003.

[53] M. O. Bahtiyar, C. Buhimschi, V. Ravishankar et al., "Contrasting effects of chronic hypoxia and nitric oxide synthase inhibition on circulating angiogenic factors in a rat model of growth restriction," American Journal of Obstetrics \& Gynecology, vol. 196, no. 1, pp. 72.e1-72.e6, 2007.

[54] I. Buhimschi, C. Yallampalli, K. Chwalisz, and R. E. Garfield, "Pre-eclampsia-like conditions produced by nitric oxide inhibition: effects of L-arginine, D-arginine and steroid hormones," Human Reproduction, vol. 10, no. 10, pp. 2723-2730, 1995.

[55] C. Yallampalli and R. E. Garfield, "Inhibition of nitric oxide synthesis in rats during pregnancy produces signs similar to those of preeclampsia," American Journal of Obstetrics \& Gynecology, vol. 169 , no. 5, pp. 1316-1320, 1993. 


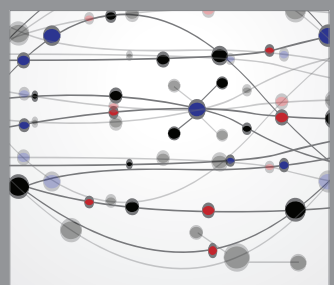

The Scientific World Journal
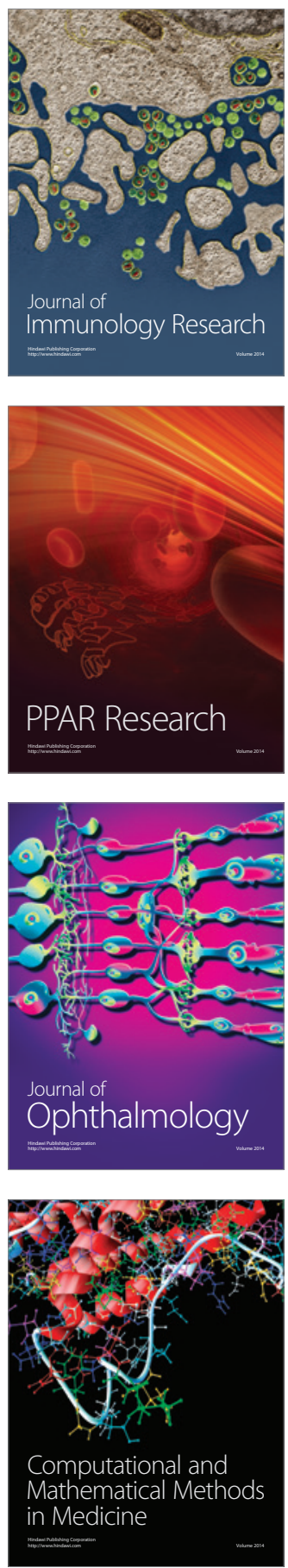

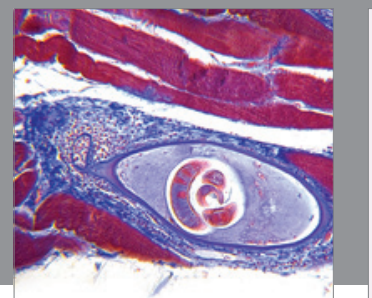

Gastroenterology

Research and Practice
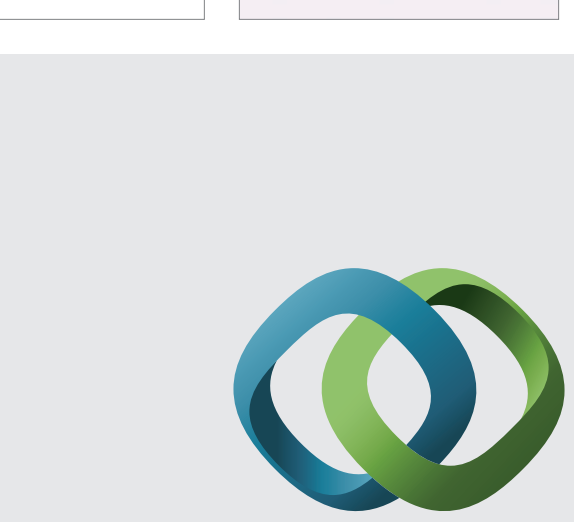

\section{Hindawi}

Submit your manuscripts at

http://www.hindawi.com
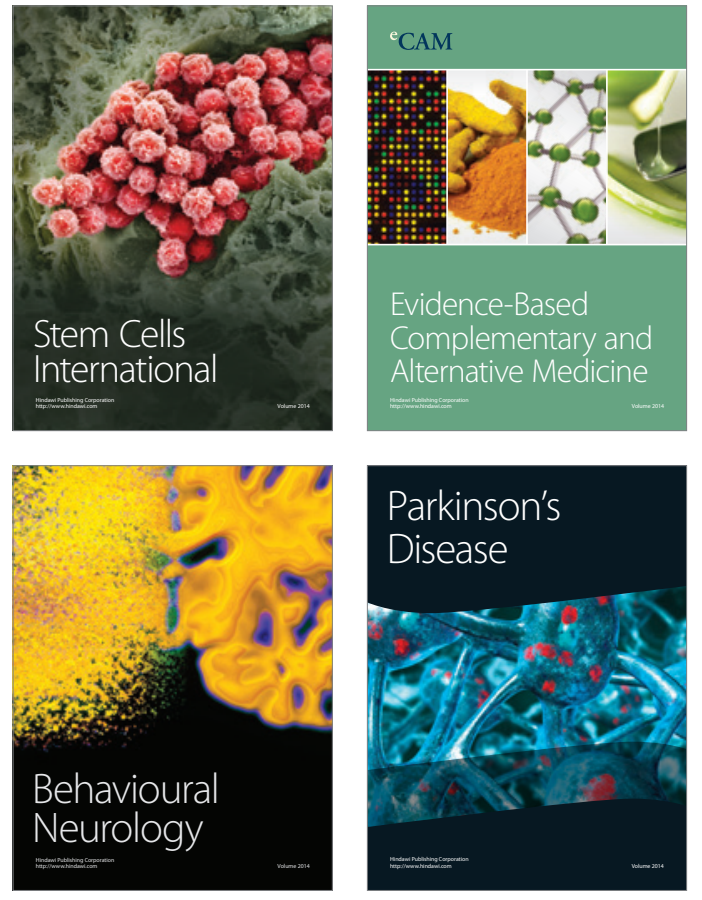
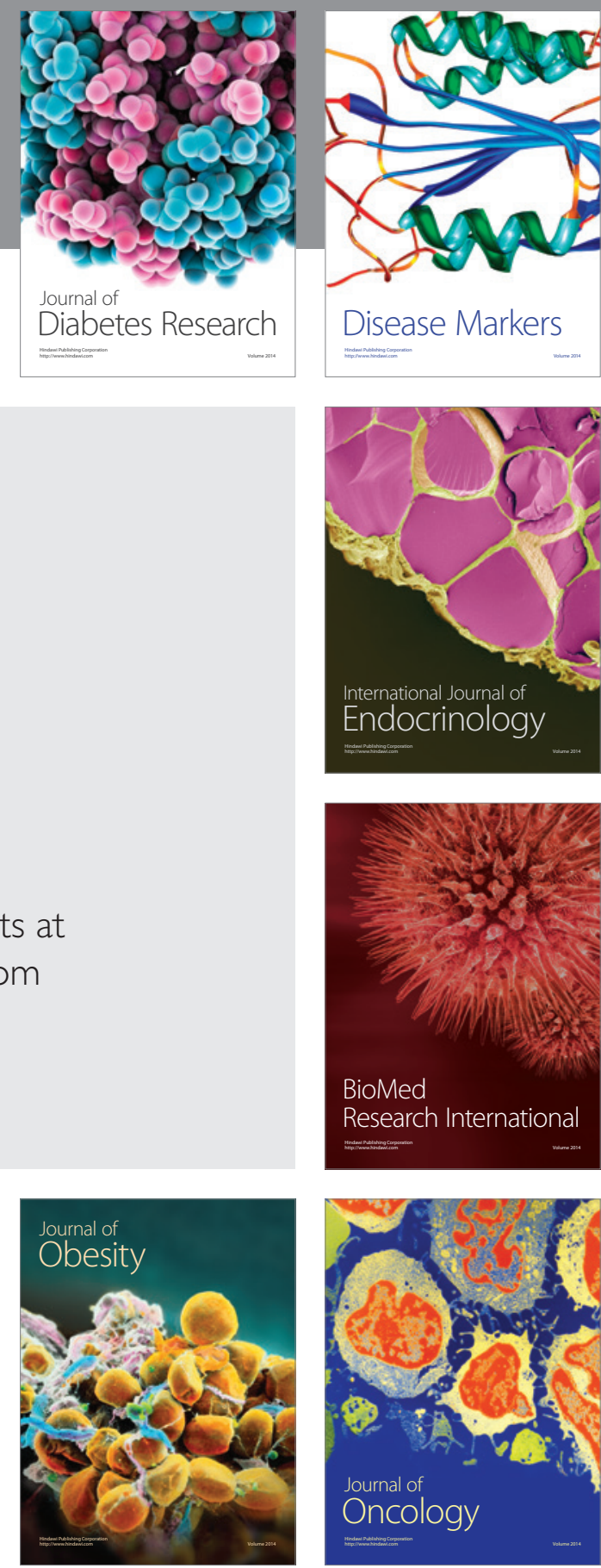

Disease Markers
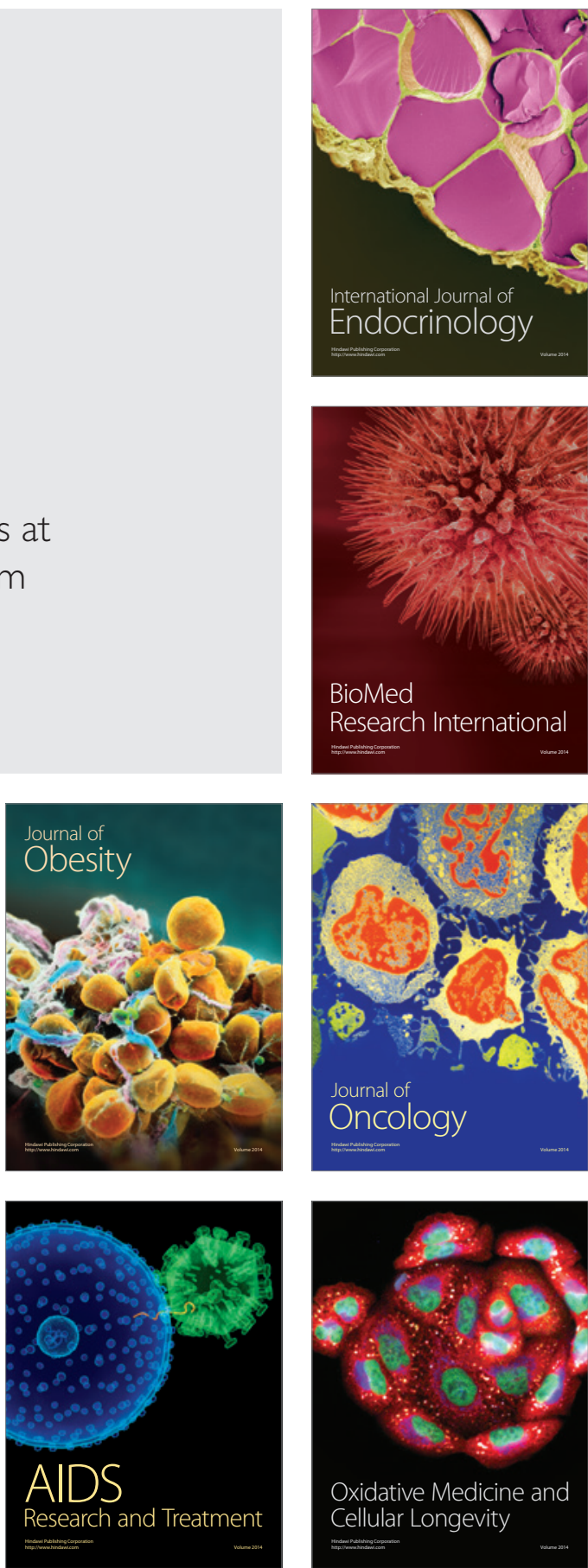